\title{
Carbonate characterization in heterogeneous reservoirs of the pré-salt using Radial Resistivity Image (RRI) and petrophysical properties in the Santos Basin, Brazil.
}

Herson Oliveira da Rocha ${ }^{1,2}$, Jéssica Lia Santos Costa ${ }^{1}$, Abel Carrasquilla ${ }^{1}$, Alfredo Carrasco ${ }^{1}$ LENEP/UENF, Macaé-RJ; ${ }^{2}$ UFRA, Parauapebas-PA; UFF, ${ }^{3}$ Niterói-RJ

Copyright 2019, SBGf - Sociedade Brasileira de Geofísica

This paper was prepared for presentation during the $16^{\text {th }}$ International Congress of the Brazilian Geophysical Society held in Rio de Janeiro, Brazil, 19-22 August 2019.

Contents of this paper were reviewed by the Technical Committee of the $16^{\text {th }}$ International Congress of the Brazilian Geophysical Society and do not necessarily represent any position of the SBGf, its officers or members. Electronic reproduction or storage of any part of this paper for commercial purposes without the written consent of the Brazilian Geophysical Society is prohibited.

\section{Abstract}

This study aims to construct Radial Resistivity Images (RRI) and analyze petrophysical properties to aid in the characterization and imaging of the drilling fluid distribution in a pre-salt carbonate reservoir in the Santos Basin, Southeastern Brazil. From the porosity and permeability samples obtained in the laboratory, it was possible to characterize the reservoir in 6 hydraulic flow units. Then, three sections of radial resistivity were created, which were based on the resistivity (laterolog and induction) logs, which examined the resistivity variation within the reservoir in surface resistivity (LLS), mean (LLM) and depth (LLD) with the acoustic image log and the NMR log. As expected, the responses presented higher values of resistivity in the zones closer to the well wall, which occurs due to the invasion of the drilling mud, since these layers present values of porosity and permeability in laboratory tests varying from 2 to $20 \%$ and 0.1 to $900 \mathrm{mD}$, respectively, which may be associated with the presence of fractures. The methodology adopted was effective to identify heterogeneities and permoporous zones.

\section{Introduction}

The oil is found inside the rock rocks, that is, in the rocks that have permeability and permeability, allowing the fluid to flow inside (Tucker, 2009). Porosity and permeability are parameters for the characterization of a reservoir and an output flow indicator, with the aim of optimizing production (Carvalho et al., 2014). The complexities of the porous system presented in the carbonate reservoirs, especially those of the Brazilian pre-salt, make their perm-porous properties difficult to quantify due to the variation in the scale of porous media. However, using radial resistivity images to verify the penetration of the drilling fluid, it is possible to analyze heterogeneities in scale and to obtain qualitative and representative data.

The objective of this work was to analyze the petrophysical properties and construct resistivity sections in a Brazilian pre-salt carbonate reservoir, trying to identify promising horizons for oil exploration and production. The porosity and permeability measurements, obtained from laboratory samples, were compared with well profiles to verify their correlations. The resistivity sections were based on well log resistivies (laterolog and induction) records, which provide shallow, medium and deep investigation distances within the reservoir.

The studies were established in the Barra Velha Formation, in the Santos Basin, which is subdivided into upper and lower sequences. The lower date of the beginning of the Aptian and is characterized by the deposition of microbial limestones, stromatolites and laminites in the proximal sections and schists in the more distant portions. There are also grainstones and packstones composed of fragments of stromatolite and bioclastic. The upper sequence dates from the Late Aptian, where there are stromatolites limestones and dolomitized microbial laminites (Moreira et al., 2007)

Thus, well logging and analysis of rock samples in the laboratory are widely used methods to evaluate the physical properties of geological formations in the petrophysical characterization of carbonate reservoirs (Aguilera \& Aguilera, 2001). The data resolution and spatial coverage in these two methods, combined with the number of measured parameters, occur in different ranges to obtain knowledge of the lithologic and subsurface structural information (Shenawi et al., 2007).

\section{Method}

The set of data provided for the development of this study started from a $25 \mathrm{~m}$ stretch of the carbonate reservoir, represented by depths 575 to 600 (fictitious values) to preserve the well identity. These data contained geological information, laboratory measurements, basic sets of well logs, acoustic imaging and Nuclear Magnetic Resonance (NMR). With this information, the first initiative was to characterize the reservoir in Hydraulic Flow Units (HFU) as proposed by Tiab \& Donaldson (2012). Then, the methodology of Winland (1972) was used to identify the radius size of the pore throat. After these steps, the lateral and intermediate surface resistivity logs (LLS, LLM and LLD), respectively, were analyzed and their values were interpolated by means of a cubic polynomial to construct a resistivity section (Rocha et al., 2018).

Similarly, the same approach was used for induction logs. In the case of Array Induction Tool (AIT) we used two resolutions, one and two feet (AO and $A T)$ with investigative capacity of $10,20,30,60$ and 90 inches, for which resistivity sections were also constructed to 
analyze the areas more resistive and correlate with mud invasion during drilling.

On the other hand, Digital Image Analyze (DIA) of plugs were analyzed to estimate petrophysical parameters such as specific surface area, specified perimeter and geometric coefficient. These parameters will be used to estimate the permeability using the Kozeny equation. NMR data were used to compare the density of the pore distribution and compare with laboratory measurements of porosity and permeability. Finally, an integrated interpretation encompassing all individual interpretations was performed. All analyzes, interpretations and data manipulation were performed using Interactive Petrophysics software (IP, 2016), Excel (EXCEL, 2016) and Matlab (2017).

\section{Results}

Initially, the correlation between porosity and permeability was verified from the values extracted from plug samples, with a value greater than $64 \%$ correlation (Figure 1). Subsequently we constructed the Modified Lorenz Graphic to identify the hydraulic flow units with the purpose of characterizing the repository. In the occasion, verified that the reservoir has a capacity for store greater than the flow capacity. In this approach, the presence of 6 units (HFU1-6) was observed, the first five being zones where the capacity of flow displacement is greater than the storage capacity and in HFU-6 the opposite occurs, that is, the storage capacity is greater than the flow capacity, thus configuring a barrier zone (Figure 2).

The Winland curves were fundamental for predicting the pore throat radius, where we observed a higher concentration of micropores, with permeability ranging from 0.01 to approximately $1 \mathrm{mD}$ and low porosity (between 2 and 12\%). This characteristic is due to the fact that this zone has undergone severe diagenetic processes (dolomitization and/or cementation). And also, the zones with better perm-porous properties, with porosity ranging from 12 to $20 \%$ and permeability of more than to $10 \mathrm{mD}$ (Figure 3).

RRls have proven to be a useful tool in reservoir interpretation, especially when used in conjunction with other profiles, although it is important to recognize the limitations of the tool to measure very high resistivity values. The laterolog presented resistivity values ranging from 0.2 to $1995 \mathrm{ohm} . \mathrm{m}$ between depths 583 and $593 \mathrm{~m}$, with a highly resistive zone in the LLS and LLM registers and lower values in the LLD curves as well as in the resistivity of the formation (track 2 in figure 4). According to Crain (1984), this scenario characterizes an invasion of mud in the reservoir when the geological formation presents hydrocarbons and fluids of the formation water.

In the case of the induction logs ( $\mathrm{AO}$ and $\mathrm{AT}$ ), the same high resistivity zone identified by the LLS and LLM logs was also identified by profiles AO-10, AO-20 and AO-30 (track 4 in figure 4). The AO-60 and AO-90 records showed higher RT values than LLD and a similar format. It is observed that the upper peak appears in all laterolog curves, in the RT curve and in all induction logs. The lower peak appears only in the LLD and AT-90 logs, as well as in the RT curve, it is, an anomaly representing a structure distant from the well wall (track 6 in figure 4). Both peaks can represent lithologic information associated with fractured zones in the reservoir.

From the resistivity logs, we created radial resistivity images (RRI) with the purpose of assisting in the imaging of the anomalies. In track 3 we have the RRI-1 obtained from the lareolog it was possible to image the process of invasion, mainly in the vicinity of the wall of the well. Track 5 shows the RRI-2 obtained with the AOT induction logs, with a vertical resolution of 1 foot, and due to this resolution, allowed to image in more detail, near the wall of the well, highlighting a complex system of fractures, the which allowed the invasion of the drilling fluid, as also observed in RRT-1.

And, the RRI-3 (track 7), derived from AIT induction logs, (resolution 2 feet) which allowed image more remote parts of the shaft wall, which identified the presence of similar structures in caves that have been confirmed by the profile acoustic image (track 8) at depths of 585 and $590 \mathrm{~m}$, respectively.

In track 8, the T2 distribution cut of the NMR profile (track 9) allowed us to analyze that the low T2 relaxation times are associated with the following factors: decrease of porosity, decrease of deep resistivities (LLD, AO-90 and AT -90) and the presence and also the presence of inclined layers.

As an example, we took three plug samples (top, middle and base) to analyze their petrographic images (Figure 5, left). The images were modified to gray scale in order to observe the behavior of both grain and pore structures. The figures were able to observe how the carbonate reservoir is heterogenous. Then the figures were binarized and the two parts analyzed (black and white), the first one being related to the matrix and the second corresponding to the porous space (Figure 5, rigth).

Another important observation to do is with respect to the fractures, which can be seen in track 8 , where the fractured zones presented smaller geometric coefficient, this due to the reason between the area of the specific surface and the specific perimeter are smaller in these zones, one these areas have partially or severely dolomitized pores.

\section{Conclusions}

The approach adopted in this study allowed a good characterization of the reservoir in hydraulic flow units. With this, the resistivity measurements clearly showed the invasion of the drilling mud inside the reservoir through the high values of resistivity in the lower depths of investigation observed mainly in laterolog profiles. From the joint analysis of the resistivity data (laterolog and induction) it was possible to construct resistivity images to infer how much the geological environment is 
heterogeneous, which can also be identified in the image $\log$.

RRIs have proven to be a useful tool in reservoir interpretation, especially when used in conjunction with other profiles, although it is important to recognize the limitations of the tool to measure very high resistivity values. The NMR distributions in the carbonates studied they belong two groups. Group 1, higher porosity and wide distribution of NMR T2 time distribution; group 2, lower porosity and bimodal NMR T2 time distribution.

The results indicate that this methodology is satisfactory for the estimation of petrophysical parameters and to correlate them with well logs.

\section{Acknowledgments}

To UENF for the structure and computational support, CAPES and PRH-226 Petrobras/UENF for scholarships, Galp Petrogal of Brazil for the dataset, and the first author also thanks UFRA for the license for professional qualification.

\section{References}

Aguilera, R. \& Aguilera, M. 2001. The integration of capillary pressures and Pickett plots for determination. SPE Conference, paper no. 71725.

Carvalho, S., Oliveira, M., Duarte, T., Duarte, M., \& Barros Neto, E. 2014. Blucher Chemical Engineering Proceedings, v. 1, n. 2, p. 13739-13745.

Crain, E. 1984. Log analysis handbook Vol. 1: Quantitative Log Analysis. Pennwell Books, Tulsa, OK. (https://www.spec2000.net/05-bibliography.htm consulted on January 5,2018$)$.

MICROSOFT EXCEL. 2016. Users' Manual.

IP. 2015. Interactive Petrophysics Users' Manual.

Moreira, J.; Madeira, C.; Gil, J. \& Machado, M. 2007. Santos Basin. Petrobras Geosciences Bulletin, Rio de Janeiro, v. 15, n. 2, p. 531-549. (In Portuguese).

Rocha, H.; Carrasquilla, A.; Costa, J.; Campi, A.; Al lahham, M., 2018. Analyzing geophysical well logs to derive petrophysical properties and resistivity sections in the identification of promising horizons for oil production in a Brazilian carbonate reservoir. 80th EAGE Conference and Exhibition 2018. Copenhagen, Denmark. DOI: $10.3997 / 2214-4609.201801282$.

Shenawi, S.; White, J.; Elrafie, E. \& El-Kilany, K. 2007. Permeability and water saturation distribution by lithologic facies and hydraulic units: a reservoir simulation case study. Presented at the SPE Middle East Oil and Gas Show and Conference, Manama, Bahrain, SPE105273.

Tiab, D. \& Donaldson, E. 2012. Petrophysics: Theory and practice of measuring reservoir rock and fluid transport properties. Gulf Professional Publishing, 3rd Edition, 950 p.

Tucker, M. 2009. Sedimentary petrology: an introduction to the origin of sedimentary rocks. John Wiley \& Sons.

Winland, H. 1972. Oil accumulation in response to pore size charges, Weyburn field, Saskatchewan. Amoco Production Company Research Department, F72-G-25. 


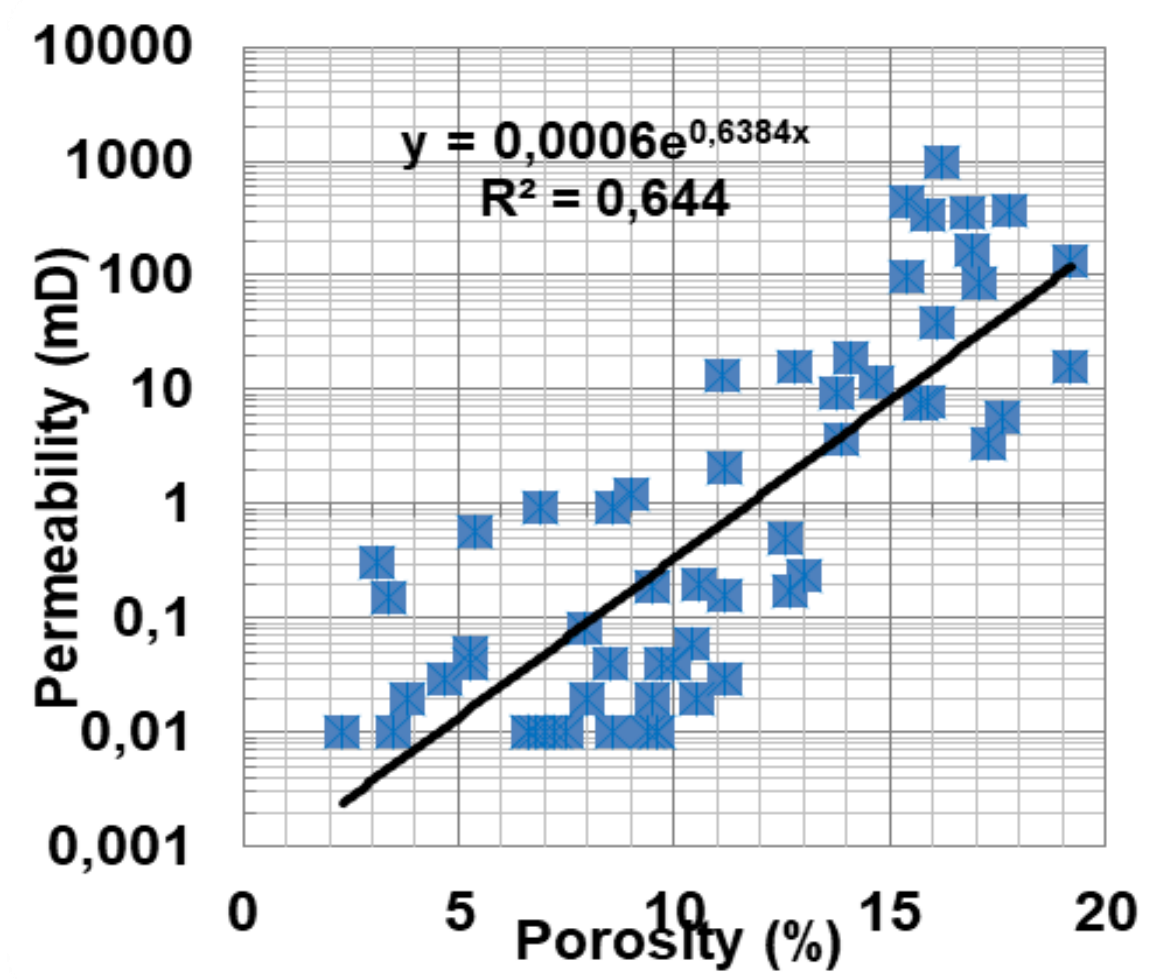

Figure 1. Cross plot porosity $x$ permeability of the carbonates in the studied.

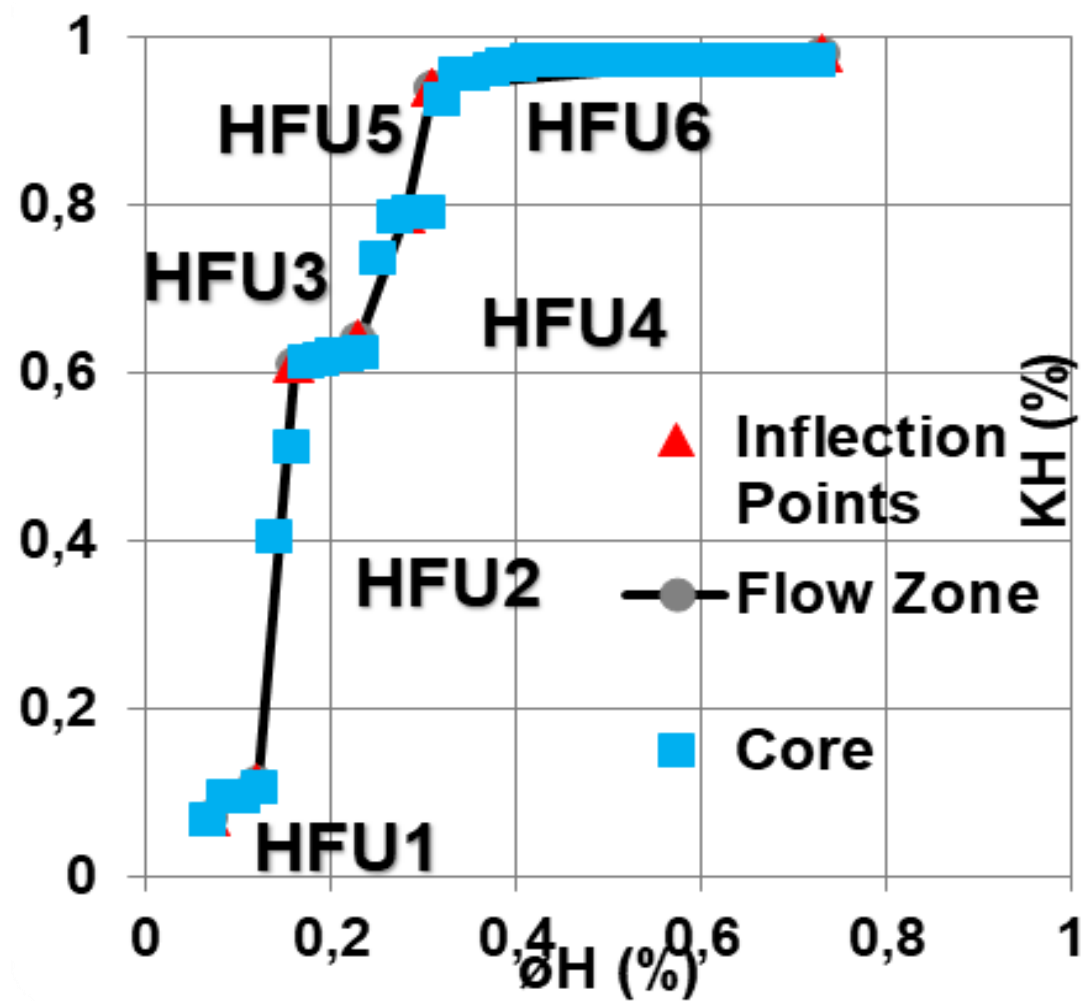

Figure 2. Modified Lorenz Graphic identifying the six hydraulic flow units. 


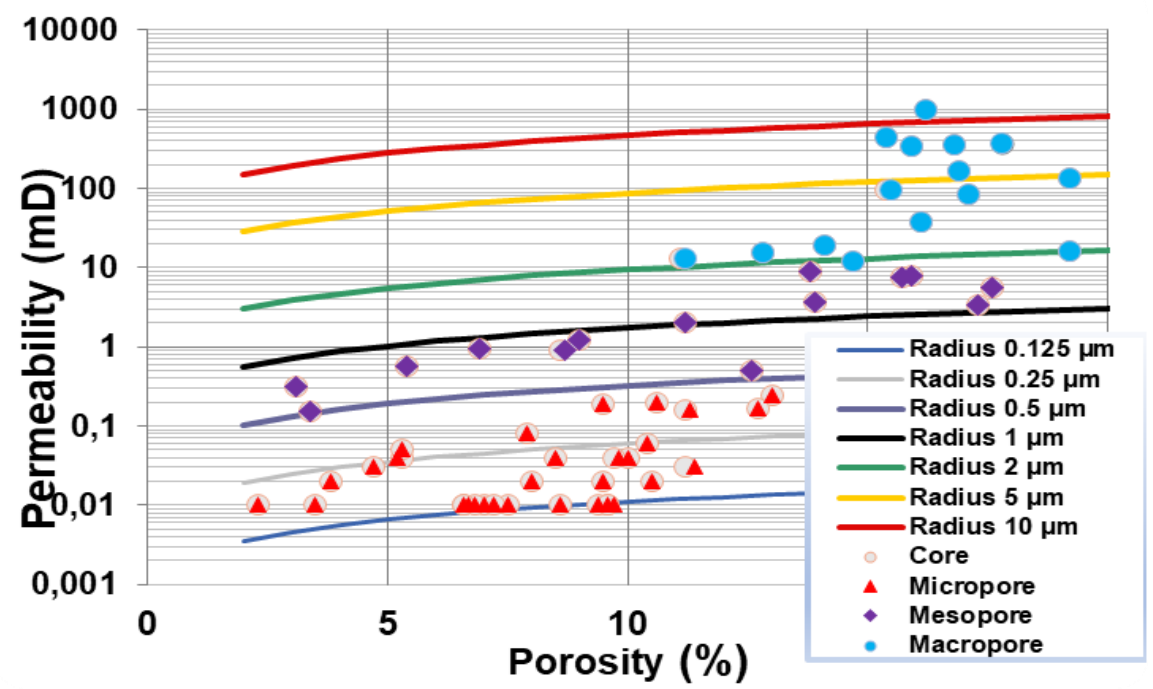

Figure 3. Winland curves with distribution the pore throat radius.

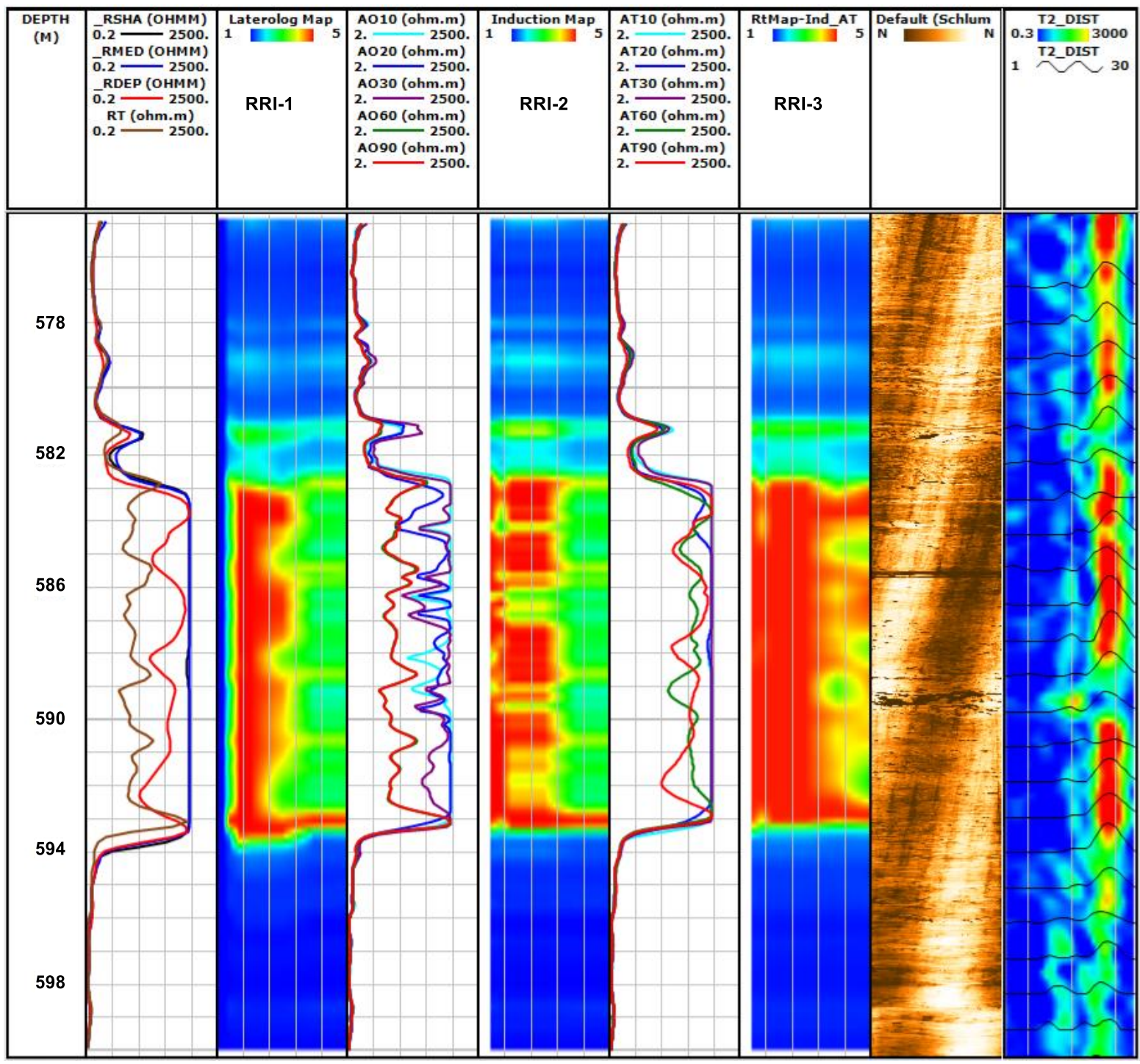

Figure 4. Depth (track 1), laterolog and induction resistivity logs (track 2, 4 and 6), RRls (track 3, 5 and 7), acoustic image $\log$ (track 8) and T2 NMR distribution (track 9). 

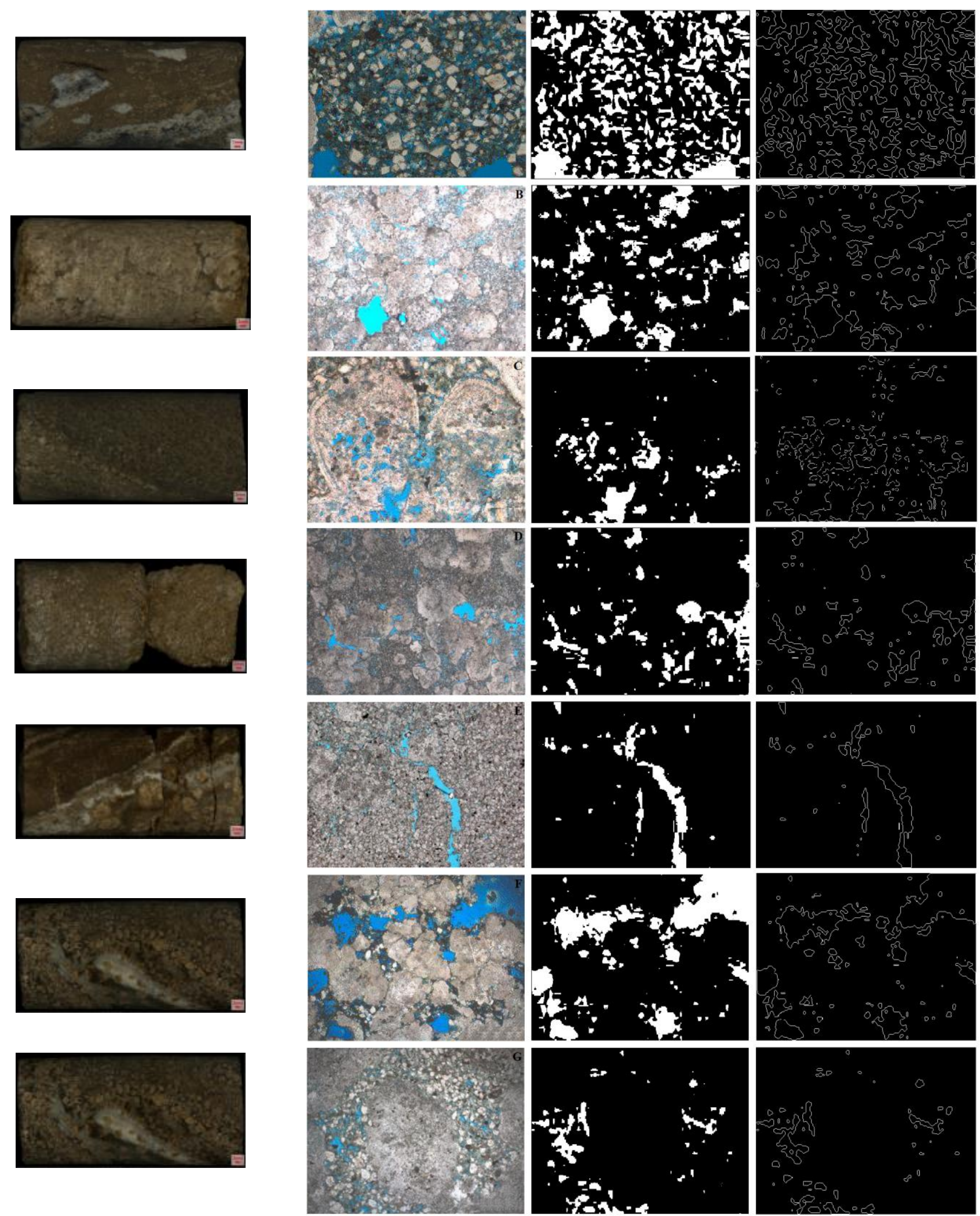

Figure 5. From left to right we have the plugs, the petrographic images, the area of the surface area and the specific perimeter. 